\title{
SEGURANÇA DE DADOS PESSOAIS NA INTERNET SOB A ÉGIDE DOS PRINCÍPIOS CONSTITUCIONAIS ${ }^{1}$
}

\author{
SECURITY OF PERSONAL DATA ON THE INTERNET UNDER THE AEGIS OF \\ CONSTITUTIONAL PRINCIPLES
}

Ingrid Almeida SILVA ${ }^{2}$

Sílvio Marques GARCIA ${ }^{3}$

ISSUE DOI: $10.21207 / 2675-0104.2019 .900$

\section{RESUMO}

Este artigo tem como objetivo analisar o contexto histórico de criação da internet, e suas implicações para o Direito Digital e o Direito Civil. Busca-se investigar a prevalência dos direitos fundamentais à privacidade e à intimidade no âmbito da web, direitos esses que estão garantidos em diversos tratados internacionais, na Constituição Federal, no Código Civil, na Lei n. 12.965/2014 (Marco Civil da Internet) e na Lei n. 13.709/2018 (Lei Geral de Proteção de Dados Pessoais). Assim, por meio do

\footnotetext{
${ }^{1} \mathrm{O}$ presente artigo sintetiza a monografia de conclusão da pesquisa, realizada para o Programa Interno de Bolsas de Iniciação Científica (PIBIC 2018-2019) da Faculdade de Direito de Franca (FDF), Franca/SP.

${ }^{2}$ Discente da Faculdade de Direito de Franca (FDF), Franca/SP. Bolsista do Programa Interno de Bolsas de Iniciação Científica (PIBIC 2018-2019).

${ }^{3}$ Doutorando em Direito (PUC/SP, 2017-Atual), Mestre em Direito (Unesp, 2013), Pós-Graduado Lato Sensu em Direito Público (UnB/Escola da AGU, 2010), Pós-Graduado Lato Sensu em Direito Penal e Processual Penal (Unifran, 2003) e Bacharel em Direito (Unesp, 2001). Procurador Federal (2007Atual). Professor de Direito Tributário e Direito Financeiro da Faculdade de Direito de Franca (FDF, 2015-Atual), admitido mediante concurso de provas e títulos. Foi Professor de Direito Financeiro e Direito Tributário no curso de Direito da Universidade Estadual Paulista (Unesp, Franca/SP, 20142015), em caráter temporário, admitido mediante concurso de provas e títulos. Possui experiência na área de Direito Público, com ênfase em Direito Tributário e Financeiro, Previdenciário, Constitucional e Administrativo. Autor do livro Aposentadoria por Idade do Trabalhador Rural e de capítulos de livros e artigos na área do Direito Público.
} 
método dedutivo, aplicado a procedimentos de pesquisa bibliográfica, avaliam-se possíveis medidas para garantir maior segurança aos dados pessoais dos usuários na rede mundial de computadores, bem como os impactos das leis de proteção aos usuários e aos dados pessoais na utilização do ambiente virtual.

Palavras-chave: Internet. Direito Digital. Privacidade. Intimidade. Dignidade da Pessoa Humana.

\begin{abstract}
This article aims to analyze the historical context of internet creation, and its implications for Digital Law and Civil Law. The focus is investigate the prevalence of fundamental rights to privacy and intimacy within in relationship to the web. These rights are guaranteed in several international treaties, in the Federal Constitution, in the Civil Code, in Law 12.965/2014 (Internet Statute) and Law 13.709/2018 (General Law for the Protection of Personal Data). Thus, through the deductive method, applied to bibliographic research procedures, possible measures are assessed to ensure greater security of users' personal data on the world wide web, as well as the impacts of laws protecting users and personal data on use of the virtual environment.
\end{abstract}

Keywords: Internet. Digital law. Privacy. Intimacy. Dignity of the human being.

1

\title{
INTRODUÇÃO
}

Este artigo tem como objetivo principal trazer à discussão a importância da proteção do direito à privacidade e à intimidade no ambiente virtual, os quais devem ser estudados a partir das garantias constitucionais. A análise da segurança dos dados sensíveis e pessoais dos usuários é extremamente relevante por conta da necessidade de proteção desses direitos. A partir do método dedutivo e por meio da leitura e análise de obras jurídicas da área e da legislação relacionada ao tema, esta pesquisa analisa a os direitos fundamentais à privacidade e à intimidade no âmbito da $w e b$, com o intuito de contribuir para a garantia da segurança dos dados pessoais dos usuários na rede mundial de computadores, com enfoque na regulamentação jurídica promovida pela Lei n. 12.965/2014, o denominado Marco Civil da Internet.

Com as mudanças tecnológicas da atualidade, é notável o descompasso entre a legislação atual e as evoluções dessas tecnologias. A grande invenção das últimas décadas certamente foi a internet, que é uma rede que liga um elevado número de computadores em todo o planeta, por meio de cabos, satélites, redes telefônicas e redes sem fio.

Apesar de não ser novidade, a internet tem promovido transformações em uma velocidade espantosa, que constitui uma barreira para a elaboração legislativa sobre assuntos digitais, pois qualquer lei que venha a tratar do assunto deve ser genérica e flexível o bastante para atender à demanda do ambiente virtual. As inovações tecnológicas exigem 
do Direito uma regulamentação satisfatória dos riscos e oportunidades advindos desses avanços. Há uma relação de imbricação entre a tecnologia e o Direito, pois este regula e limita a atividade humana no ambiente virtual.

A criação da Internet permitiu a consolidação da Era da Informação (pós-Era Industrial) e o surgimento de três elementos na rede: a velocidade (cada vez maior quanto à transmissão de conhecimentos e informações entre usuários), a origem descentralizada das informações e a sua inesgotabilidade. Na Era Industrial, cada bem de consumo produzido era indivisível e possuía um único fim. Atualmente, porém, na Era da Informação, os bens podem ser replicados infinitamente por qualquer usuário. Esse é um desafio para o Direito, que se dispõe a definir limites legais, territoriais, físicos etc. em favor do respeito aos direitos individuais. Cabe ao Direito lidar com a contradição entre globalização e liberdades versus individualização, privacidade e intimidade.

O bem jurídico tutelado pela e recente área do Direito denominada Direito Digital é constituído por dados e informações, os quais extrapolam os aspectos íntimos da personalidade da pessoa. Trata-se de um ramo autônomo do Direito, que tratar somente de assuntos digitais.

A informação, destarte, é o principal objeto dessa nova área do Direito. Assim, a proteção dos dados e informações que dizem respeito à intimidade e à privacidade é um dos princípios basilares dessa ciência. Do fato de as informações e dados pessoais dos usuários terem se transformado em moeda de troca exsurge o conflito entre direitos (de acesso ao conteúdo e de privacidade) e a urgente necessidade de proteção das relações virtuais em seus mais diversos aspectos.

\section{SURGIMENTO E EVOLUÇÃO DA INTERNET}

A Internet permitiu a virtualização de vários setores da sociedade ou a desterritorialização do espaço, isto é, a interligação virtual entre empresas e pessoas em diferentes países. Como afirmam Almeida e Silveira: “... o ciberespaço proporciona comunicação intraplanetária, o que importa na desterritorialização do espaço cibernético, pois os agentes que 
utilizam a internet como meio de comunicação não sofrem limitação de tempo de relógio ou de espaço territorial."

Com isso, verifica-se maior facilidade de realização de operações comerciais e bancárias e de troca de informações e conhecimentos. Isso acaba provocando também a "virtualização" de problemas. Dessa forma, na Era Digital, ocorreu uma revolução nas relações pessoais, sociais e comerciais, com a possibilidade de interação e de recebimento de informações vindas de qualquer lugar do mundo, relações essas que se tornaram descentralizadas, diversificadas e democratizadas.

A rede virtual surgiu no contexto da Guerra Fria, em uma disputa tecnológica, com uma necessidade militar estadunidense de impedir um ataque soviético às bases militares de inteligência foi idealizado um modelo de projeto de troca e compartilhamento de informações, permitindo a descentralização e a segurança destas. Com a criação da ARPANET, que nasceu em uma agência militar de pesquisas ligada ao Departamento de Defesa dos EUA, a ARPA, criada em 1958, visando à criação de pequenas redes locais estrategicamente posicionadas pelo país e ligadas por meio de redes de telecomunicação geográfica, formando de uma teia de conexões. ${ }^{5}$ Foi, entretanto, em 1973 que houve o grande crescimento, quando o Departamento de Pesquisa Avançada da Universidade da Califórnia e responsável pelo projeto, registrou o Protocolo TCP/IP (código que permite a integral comunicação entre programas e sistemas).

A vida em sociedade fez surgir várias esferas de relacionamento do ser humano, as quais se transformaram ao longo dos séculos. Atualmente, existem três esferas: pública, privada e virtual. Para Habermas, "O sujeito dessa esfera pública é o público enquanto portador da opinião pública." ${ }^{\circ}$ A esfera virtual é considerada uma extensão da esfera tradicional, o ciberespaço. Se, antes, bastavam as declarações de direitos para que os indivíduos se respeitassem nas esferas social e privada, hoje se faz cada vez mais necessária a reafirmação dos limites entre indivíduo e Estado na esfera virtual. A Internet, por ser um território à parte do mundo físico, demanda legislação própria.

\footnotetext{
${ }^{4}$ ALMEIDA, Patricia Martinez; SILVEIRA, Vladmir Oliveira da. Processo judicial eletrônico e segurança de dados: a proteção digital como novo direito humano. Revista Mestrado em Direito, Osasco, v. 13, n. 2, p. 323-343 jul-dez. 2013. p. 331.

${ }^{5}$ Daí a referência às palavras "net", que em inglês significa rede, e "web", que faz referência às teias de aranhas.

${ }^{6}$ HABERMAS, Jürgen. Mudança estrutural na esfera pública: investigações quanto a uma categoria da sociedade burguesa. 2.ed. Rio de Janeiro: Tempo Brasileiro, 2003. p. 14.
} 
Nesta cena, o estudo da Regulamentação e Efetividade Jurídica da Sociedade da Informação adquire status estratégico, uma vez que novas relações sociais, interpessoais e interinstitucionais, muitas vezes travadas em cenário internacional, exige uma nova reflexão sobre paradigmas, teorias e aplicação do Direito que, como fato social, não pode se manter indiferente aos novos arranjos e contornos desse novo modelo de sociedade. ${ }^{7}$

Essa tensão fez surgir regras jurídicas que no seu conjunto constituem o Direito Digital, o qual, segundo Patrícia Peck Pinheiro, pode ser assim conceituado:

O Direito Digital consiste na evolução do próprio Direito, abrangendo todos os princípios fundamentais e institutos que estão vigentes e são aplicados até hoje, assim como introduzindo novos institutos e elementos para o pensamento jurídico, em todas as suas áreas (Direito Civil, Direito Autoral, Direito Comercial, Direito Contratual, Direito Econômico, Direito Financeiro, Direito Tributário, Direito Penal, Direito Internacional etc. $)^{8}$

\section{A autora complementa, ainda, que:}

o Direito Digital traz a oportunidade de aplicar dentro de uma lógica jurídica uniforme uma série de princípios e soluções que já vinham sendo aplicados de modo difuso - princípios e soluções que estão na base do chamado Direito Costumeiro. Esta coesão de pensamento possibilita efetivamente alcançar resultados e preencher lacunas nunca antes resolvidas, tanto no âmbito real quanto no virtual, uma vez que é a manifestação de vontade humana em seus diversos formatos que une estes dois mundos no contexto jurídico. Logo, o Direito Digital estabelece um relacionamento entre o Direito Codificado e o Direito Costumeiro, aplicando os elementos que cada um tem de melhor para a solução das questões da Sociedade Digital. ${ }^{9}$

A proteção jurídica oferecida por esse novo ramo do Direito alcança não somente os dados pessoais estritamente íntimos dos indivíduos, mas também amplia a salvaguarda aos dados não propriamente íntimos, que fornecem dados essenciais sobre o usuário.

\section{A informação é o principal objeto do Direito Digital e sua proteção é um dos princípios basilares dessa área. Pelo fato de as}

\footnotetext{
${ }^{7}$ BARRETO JR., Irineu Francisco. Dignidade da pessoa humana na Sociedade da Informação. In: SIMÃO FILHO, Adalberto et al (org e coord). Direito da Sociedade da Informação: temas jurídicos relevantes. São Paulo: Quartier Latin, 2012. p.15

${ }^{8}$ PINHEIRO, Patrícia Peck. Direito Digital. 6 ed. São Paulo: Editora Saraiva, 2016. p. 79. p. 77.

${ }^{9}$ PINHEIRO, Patrícia Peck. Direito Digital. 6 ed. São Paulo: Editora Saraiva, 2016. p. 79.
} 
informações e dados pessoais dos usuários terem se transformado em produto de altíssimo valor para diversas empresas, surge o conflito entre a liberdade de utilização (de acesso ao conteúdo) e a necessidade de proteção dos dados.

Não existe lesão ao direito à privacidade se houve consentimento do titular dos dados pessoais e informações acerca do fato, como na aceitação de termos de uso de um site. No entanto, atualmente, os sites, softwares e aplicativos eletrônicos têm como regra exigido acesso total a várias informações pessoais do indivíduo, como seus documentos, localização geográfica e, inclusive, acesso a microfones e câmeras dos aparelhos. Aquele que decide se conectar aceita, mesmo que tacitamente, o resultado da "socialização dos seus dados" nas redes sociais, ou melhor, a perda do controle das suas próprias informações.

Há um preço a pagar para que o sujeito possa sentir-se inserido no mundo digital ou possa utilizar diversos aplicativos oferecidos gratuitamente (como Facebook, Hotmail, Google, Youtube, etc), havendo uma troca de conteúdos digitais de interesse comum pelos respectivos dados da intimidade e da privacidade. Essa gratuidade é questionada especialmente pelo fato de ocorrer essa troca dos direitos fundamentais de intimidade e privacidade pela exposição social e inclusão tecnológica, por meio dessas plataformas. A opção do usuário por compartilhar certos dados ou informações na galáxia da internet afeta diretamente sua vida, pois com a infinitude do espaço virtual e com a existência da deep web, não se sabe até onde e até quando tais elementos permanecerão nesse ambiente.

A Revolução Digital acarretou maiores alterações na vida das pessoas e em ritmo muito mais acelerado do que a Revolução Industrial. No século XXI foi construído um novo mundo e um novo espaço, o ciberespaço. Com essa nova realidade, o desafio em oferecer novas soluções eficientes para os problemas práticos no limitado sistema jurídico existente. É fundamental e desafiador criar novas interpretações dos institutos jurídicos já existentes e também utilizar a própria arquitetura da internet conjuntamente com o sistema jurídico, isto é, os mecanismos tecnológicos podem ser utilizados para intencionalmente restringirem o comportamento de seus usuários, forçando-os a certas condutas ou possibilitando ao sistema jurídico coibir determinadas práticas.

De forma pioneira, a Inglaterra, em 1969, teve o primeiro projeto de lei com a finalidade impedir toda e qualquer intromissão na intimidade dos indivíduos por meio do uso irregular de informações contidas em 
computadores. Apesar da sua não aprovação, houve diversas reações de alguns setores. Nos EUA, a discussão também é antiga. Até 1970, existia um vazio legal quanto à proteção de dados, mas a partir desse ano o Fair Credit Reporting Act surgiu com a finalidade de proteger os clientes das sociedades de crédito quanto ao uso indevido das informações contidas nos seus bancos de dados. Em 1974. surgiu o Privacy Act, documento que reconhece o direito, de todo indivíduo, de tomar ciência das informações que dizem respeito a sua pessoa e de modificá-las ou cancelá-las, caso não sejam corretas ou versem sobre assuntos não autorizados. Posteriormente, surgiu o Privacy Protection Act, cujo texto estabeleceu novas limitações às investigações e à intervenção nas documentações privadas e instituiu os ressarcimentos para as vítimas de violações quanto ao seu direito à privacidade. $^{10}$

\section{PROTEÇÃO À INTIMIDADE E PRIVACIDADE NA ERA DIGITAL}

Como observa Marcel Leonardi, tanto a Constituição Federal, quanto o Código Civil de 2002 não utilizar o termo privacidade, mas sim as expressões vida privada e intimidade. ${ }^{11}$ Trata-se de expressões relacionadas à esfera do privado, aquilo que se passa na vida íntima do indivíduo, cuja divulgação deve permanecer na esfera da sua discrição. A privacidade, para o direito, relaciona-se com o exercício da liberdade de divulgação dos aspectos íntimos e pessoais da vida. Trata-se a privacidade de um atributo privacidade é fundamental para a formação do indivíduo como pessoa humana.

Com relação à privacidade, Danilo Doneda conceitua:

Ao se tratar da privacidade, há de se fazer antes de tudo um esclarecimento inicial sobre a terminologia utilizada. A profusão de termos utilizados pela doutrina brasileira para representá-la, propriamente ou não, é considerável; além de 'privacidade' propriamente dito, podem ser lembrados os termos: vida privada, intimidade, segredo, sigilo, recato, reserva, intimidade da vida privada, e outros menos utilizados, como 'privatividade' e 'privaticidade', por exemplo. O fato da doutrina estrangeira apontar

${ }^{10}$ GUIDI, Guilherme Berti de Campos. Modelos regulatórios para proteção de dados pessoais. In: BRANCO, Sérgio; TEFFÉ, Chiara de. Privacidade em perspectiva. Rio de Janeiro: Lumen Juris, 2018. p. 96.

${ }^{11}$ LEONARDI, Marcel. Tutela e privacidade na Internet. São Paulo: Editora Saraiva, 2012. p. 46. 
igualmente para uma multiplicidade de alternativas certamente contribui, induzindo juristas brasileiros a experimentar diversas destas. $^{12}$

Atualmente, o tema é imensamente relevante, visto que com a maior possibilidade de acesso à internet, especialmente após o advento da geração de telefones celulares capazes com acesso às plataformas digitais, e o consequente aumento da troca de informações e dados pessoais, há um maior movimento de usuários pela rede, do que são exemplo a coleta das declarações de ajuste anual do imposto de renda pela Receita Federal, que é feita totalmente de forma digital, a quantidade de transações bancárias já realizadas de forma digital, bem como as vendas feitas pela internet, que ano após ano vem se intensificando e ganhando mais espaço no cotidiano dos usuários.

Nesse cenário, cabe lembrar que todas as transações feitas são registradas, incluindo aí os resultados da interação entre os usuários e as plataformas digitais, bem como suas preferências, desejos, intensões de compra e diversos outros dados que mapeiam seu perfil como clientes. Esses rastros deixados pelo usuário podem ser conscientes, ou não, pois pode ocorrer a partir de diversas situações como o preenchimento de formulários em compras online, cadastros e outros, termos de privacidade não lidos, além da atuação dos cookies e outros programas de rastreamento, dentre outros exemplos, sem contar a possibilidade de obtenção de informações por diversos programas maliciosos (malware), como vírus, worms, cavalos de Tróia etc.

No ambiente virtual, é necessária a discussão jurídica atrelada aos recursos tecnológicos para uma maior proteção da segurança dos dados pessoais sob a égide dos princípios constitucionais.

Nos dizeres de Celso Antonio Pacheco Fiorillo,

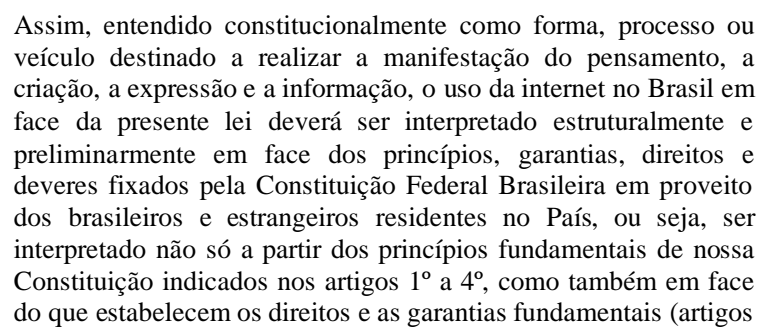

\footnotetext{
${ }^{12}$ DONEDA, Danilo. Da privacidade à proteção de dados pessoais. Rio de Janeiro: Renovar, 2006. p. 101.
} 
$5^{\circ}$ a 17$)$ bem como as regras superiores que definem as relações normativas no plano da comunicação social (artigos 220 a 224 da CF). ${ }^{13}$

Nesse sentido, não se pode esquecer que, conforme exarado pelo Superior Tribunal de Justiça em 2018,

os direitos à intimidade e à proteção da vida privada, diretamente relacionados à utilização de dados pessoais (...) consagram o direito à autodeterminação informativa e encontram guarida constitucional no art. $5^{\circ}, \mathrm{X}$, da Carta Magna, que deve ser aplicado nas relações entre particulares por força de sua eficácia horizontal e privilegiado por imposição do princípio da máxima efetividade dos direitos fundamentais. (BRASIL. Superior Tribunal de Justiça. EDcl no REsp 1630889/DF, Rel. Ministra NANCY ANDRIGHI, Terceira Turma, julgado em 27/11/2018, publicado no DJe em 06/12/2018)

A intimidade e a privacidade dos usuários podem ser tuteladas com a utilização da teoria das esferas, desenvolvida pelo Tribunal Constitucional Alemão, a qual reconhece a existência de diferentes gradações jurídicas. Por meio dessa teoria é possível distinguir três esferas: a intimidade, a vida privada e a pública. De forma decrescente, haverá a proteção de cada uma dessas esferas relacionadas a assunto determinado.

No âmbito da privacidade e da intimidade dos usuários é de se pressupor que a ampliação da convivência na rede também aumente a potencialidade lesiva aos direitos e às informações das pessoas. As informações e os dados pessoais possibilitam o mapeamento de perfis e o conhecimento das características dos usuários-consumidores. Porém, há outras situações em que essa segurança é essencial para a proteção dos direitos fundamentais, como a utilização dessas informações pelo governo e outros segmentos ligados à política, por hackers e outros agentes que atuam de forma ilícita.

O conceito de privacidade como "autodeterminação informativa" consiste na faculdade de a pessoa controlar a exposição de sua vida íntima, sua imagem, sua reputação, bem como a própria disponibilidade de informações acerca de si para terceiros fora das hipóteses excetuadas por lei, como nos casos em que houver interesse público no conhecimento daquela informação. ${ }^{14}$ Há diversos meios que possibilitam lesionar o

\footnotetext{
${ }^{13}$ FIORILLO, Celso Antônio Pacheco. O Marco Civil da Internet e o Meio Ambiente Digital na Sociedade da Informação. 2. ed. São Paulo: Editora Saraiva, 2015. p. 16.

${ }^{14}$ DONEDA, Danilo. Da privacidade à proteção de dados pessoais. Rio de Janeiro: Renovar, 2006. p. $109-113$.
} 
direito à privacidade e à intimidade dos usuários para obter vantagens, tais como: fraude eletrônica (consiste em uma mensagem não solicitada que se passa por comunicação de uma instituição conhecida e procura induzir usuários ao fornecimento de dados pessoais e financeiros), phishing scan (um código malicioso é enviado por e-mail para a vítima, a qual, não analisando a veracidade do conteúdo e nem o remetente da mensagem, executa o arquivo, acarretando a instalação de programas espiões no computador. Nesses casos, suas informações confidenciais, como CPF, endereço, renda mensal, nome de usuário, senha, cadastro de clientes e outros dados pessoais são transmitidas para o fraudador.

É necessário destacar que a Constituição Federal Brasileira de 1988 protege o direito à privacidade e à intimidade e, também, estabeleceu que os direitos nela expressos não excluem outros decorrentes dos princípios por ela adotados ou dos tratados internacionais em que o Brasil seja parte. Isso é extremamente relevante, pois a privacidade é reconhecida como um direito fundamental em praticamente todos os tratados e convenções internacionais de direitos humanos ratificados pelo Brasil. Nesse aspecto, a Declaração Americana dos Direitos e Deveres do Homem estipula que "toda pessoa tem direito à proteção da lei contra os ataques abusivos a sua honra, a sua reputação e a sua vida particular e familiar" e a Declaração Universal dos Direitos Humanos estabelece que "ninguém será sujeito a interferências na sua vida privada, na sua família, no seu lar ou na sua correspondência, nem a ataques a sua honra ou reputação. Todo indivíduo tem direito à proteção da lei contra tais interferências e ataques". Além desses tratados, a Convenção Americana de Direitos Humanos (Pacto de San José da Costa Rica) prevê que "toda pessoa tem direito ao respeito da sua honra e ao reconhecimento de sua dignidade e que ninguém pode ser objeto de ingerências arbitrárias ou abusivas em sua vida privada, (...), nem de ofensas ilegais à sua honra ou reputação".

A privacidade e outros direitos fundamentais passaram a ser reconhecidos como princípios jurídicos. $\mathrm{O}$ principal marco do reconhecimento do direito à intimidade como inerente ao ser humano e da internacionalização da proteção dos direitos humanos foi a Declaração Universal dos Direitos Humanos (1948). A partir desse documento surgiram outros, como a Convenção Americana de Direitos Humanos de 1969.

Para que uma sociedade informatizada seja verdadeiramente democrática, impõe-se que seja disponibilizado acesso à rede para todos os cidadãos. Porém, essa medida trará maior quantidade de informações 
transmitidas e irá acarretar a necessidade de respeito à privacidade dos titulares. A própria ampliação dos direitos fundamentais, dessa forma, impõe a necessidade de busca pelo equilíbrio entre ampliação do acesso e garantia da privacidade.

$\mathrm{Na}$ busca de tal equilíbrio, cabe, inicialmente observar a legislação já existente, como os direitos e os deveres (individuais e coletivos) previstos na Constituição Federal, a Lei do Marco Civil da Internet, a Lei de Proteção de Dados Pessoais, e, também, utilizar subsidiariamente as legislações e tratados internacionais.

A evolução da tutela da privacidade levou a um cenário em que o cerne do direito não está mais na garantia do isolamento e do segredo, mas, sim, no controle da circulação das informações pessoais. Ocorre, portanto, uma transformação na definição do direito à privacidade, do "direito a ser deixado em paz" para o direito de controlar as informações referentes a si próprio, sendo esta denominada de "autodeterminação informativa". Porém, é necessário ponderar que "o simples reconhecimento normativo do direito à autodeterminação informativa não terá o condão de alterar a realidade se esse dispositivo não estiver acompanhado de outras medidas políticas e da mudança de postura por parte de tomadores e fornecedores de serviços online." ${ }^{\text {" }}$

No cenário de existência das três esferas (pública, privada e virtual), o controle e a vigilância constantes existentes nesta última foi observado, principalmente, a partir da "Guerra contra o Terror" após os atentados ocorridos nos EUA no dia 11 de Setembro de 2001. Porém, foi a partir do Caso Snowden, ${ }^{16}$ em 2013, que ganharam notoriedade o aumento da preocupação com a proteção da privacidade virtual e a forma de atuação do governo em relação a esse direito. Desde então, os governos brasileiro e alemão, ambos vítimas de espionagem, encaminharam à Organização das Nações Unidas um projeto de resolução intitulado "O direito à privacidade na era digital", que contém disposições relacionadas ao Marco Civil da Internet e outros documentos legais, expressando preocupação com o uso

\footnotetext{
${ }^{15}$ SILVA, Letícia Brum da; SILVA, Rosane Leal da. A proteção jurídica de dados pessoais na internet: análise comparada do tratamento jurídico do tema na União Europeia e no Brasil. Disponível em: http://www.publicadireito.com.br/artigos/?cod=e4d8163c7a068b65. Acesso em 25 set. 2019.

${ }^{16}$ Em 2013, Edward Snowden, ex-técnico da CIA, foi acusado de espionagem por repassar informações sigilosas dos Estados Unidos e revelar detalhes de programas de vigilância utilizados para vigiar a população americana. O caso teve reflexos em vários países da Europa e inclusive no Brasil. Snowden divulgou que os EUA fizeram o monitoramento de conversas da presidente Dilma Rousseff com seus assessores. Desde então, Edward Snowden vive na Rússia, onde recebeu asilo temporário.
} 
das novas tecnologias de informação e de comunicações para a vigilância, interceptação e controle de dados.

Além dos diversos tratados de direitos humanos que garantem o direito à privacidade em que o Brasil está incluído, cabe destacar, quanto ao cenário de produção legislativa nacional, que em 2011 foi editada a Lei de Acesso à Informação (Lei n. 12.527/2011), que regulamenta o direito constitucional de acesso às informações públicas, a partir da criação de mecanismos que possibilitam a qualquer pessoa, física ou jurídica, sem necessidade de apresentar motivo, o recebimento dessas informações públicas dos órgãos e entidades.

\section{O MARCO CIVIL DA INTERNET E A LEI DE PROTEÇÃO DE DADOS PESSOAIS}

Nesse contexto de preocupação com a regulamentação de situações existentes na internet, antes do surgimento da lei conhecida como "Marco Civil da Internet", alguns princípios de governança já eram (e continuam sendo) estabelecidos pelo Comitê Gestor da Internet, tais como a proteção da liberdade, privacidade e direitos humanos, a governança democrática e colaborativa, a diversidade, a universalidade, a inovação, a neutralidade da rede, a funcionalidade, a segurança, a padronização e a interoperabilidade e outros, todos de alguma forma tratados pelo Marco Civil.

O governo brasileiro percebeu que a lei que criou o Marco Civil da Internet seria necessária para regulamentar a proteção de dados, buscando conceder aos usuários maior tutela do direito à privacidade. Esse dispositivo legal é dividido em cinco capítulos, distribuídos da seguinte forma: o primeiro trata das disposições preliminares, o segundo dos direitos e das garantias dos usuários, o terceiro trata da chamada provisão de conexão e de aplicações de internet, o quarto trata da requisição judicial de dados registrados de conexão e de acesso a aplicações de internet e o quinto e último se refere à atuação do Poder Público.

A Lei n. 12.965/2014 surgiu também como alternativa à "Lei Azeredo" (Lei n. 12.735/2012), a qual passou por diversas mudanças desde 1999 e em 2012 foi aprovada com texto reduzido e que se complementa com a Lei "Carolina Dieckmann" (Lei n. 12.737/2012). Essa Lei n. 12.735/2012 propunha ampla legislação criminal para a internet, 
provocando grandes retrocessos, visto que transformava em crimes condutas comuns na rede, praticadas por milhões de pessoas e ocasionando, assim, a possibilidade de ocorrer um engessamento na inovação tecnológica no Brasil. Ocorreu grande discussão acerca do fato de a primeira regulação da internet aprovada ser tratada pelo âmbito criminal, isto é, criminalizando diversas condutas em vez de cuidar dos direitos dos cidadãos no mundo virtual, como o direito à privacidade.

Com o Marco Civil da Internet, passou-se a desenvolver, a partir da formação da base normativa para proteção dos direitos fundamentais dos indivíduos, sem foco na repressão e punição. Criou-se uma base de proteção para os direitos e liberdades civis na internet, que se traduz nos princípios fundamentais da Constituição Federal para o território virtual. O processo de elaboração dessa lei iniciou em 2009, a partir da procura do Ministério da Justiça por uma equipe de professores do Centro de Tecnologia e Sociedade da Fundação GV. Ocorreu, ademais, uma série de consultas públicas para o primeiro texto, o qual foi levado para Câmara em 2011, além de alguns encontros com diversos setores, por meio de sete audiências públicas para discussão e aprimoramento do texto.

Em 2012, o texto do projeto de lei foi colocado no portal eDemocracia (plataforma colaborativa online para debate), para a participação da população com sugestões e críticas. Também foram considerados os comentários feitos nas redes sociais, como o Facebook e o Twitter. Após a redação final, articulada pelo Ministério da Justiça e pelos professores da FGV com a colaboração dos internautas, o texto foi analisado em âmbito governamental, com apoio de mais três Ministérios (Ciência e Inovação, Cultura e Comunicações) e, finalmente, foi encaminhado para o Congresso. No âmbito de produção da Lei n. 12.965, o processo foi dividido em duas fases, uma em que se debateram os princípios norteadores para a regulação da Internet, permitindo formar uma base principiológica, e outra de construção do texto legal, com o uso e a análise dos princípios e a comparação com a legislação de outros países. ${ }^{17}$

O objetivo do Marco Civil da Internet é estabelecer o conjunto de direitos e deveres aplicáveis aos usuários da Internet, provedores e Poder Público, proporcionando, na medida do possível, harmonização entre o Direito e a Internet. Essa lei garante a possibilidade de o Brasil participar

\footnotetext{
${ }^{17}$ LEMOS, Ronaldo. A sociedade contra-ataca: o marco civil como símbolo do desejo por inovação do brasil. Revista Observatório Itaú Cultural, São Paulo, Itaú Cultural, 20n. 16, p. 92-104. Disponível em: https://itsrio.org/wp-content/uploads/2017/01/OBSERVATORIO16 0.pdf. Acesso em: 26 jun. 2019. p. 94.
} 
das inovações globais, a partir de uma infraestrutura jurídica sem a qual haveria grande insegurança jurídica, pois as decisões judiciais não teriam parâmetros a seguir, podendo, inclusive ser contraditórias. O Marco Civil garante os direitos e os deveres dos usuários da rede e as obrigações das empresas e de outros participantes.

Ademais, a participação democrática em torno do projeto levou ao debate inédito em múltiplas plataformas digitais contribuição para a formação de uma nova metodologia de construção legislativa. ${ }^{18}$ Possibilitou, com isso, a discussão sobre os caminhos para ampliação da democracia em uma sociedade cada vez mais digital, com um processo legislativo construção aberta e colaborativa, mostrando-se uma inovação política.

A Lei n. 12.965 de 2014 pode ser considerada um importante pilar para a sociedade brasileira e fundamental para o ponto de vista do desenvolvimento futuro do Brasil, pois traz um rol de princípios basilares necessários para a proteção dos usuários.

Quanto à incorporação dos valores e princípios constitucionais no Marco Civil da Internet, Willis Guerra Filho e Henrique Garbellini Carnio explicam:

\begin{abstract}
Com relação à proteção da privacidade dos usuários é estabelecido pelo art. $3^{\circ}$ que a privacidade ganha o status de ser um dos princípios do uso da Internet no Brasil. Já no art. $7^{\circ}$, dentre os direitos dos usuários temos o direito à inviolabilidade da intimidade e da vida privada. ${ }^{19}$
\end{abstract}

Quanto à privacidade, o Marco Civil estabelece uma regra universal, que diz que nenhum dado do usuário pode ser acessado sem prévia ordem judicial que autorize esse acesso, estabelecendo ainda que deve haver consentimento livre, expresso e informado do usuário. Além disso, fixa quais são os critérios para que juízes possam autorizar ou não o acesso a esses dados. É oportuno lembrar que no Brasil o acesso aos dados e às condutas dos usuários era feito de forma indiscriminada, com

\footnotetext{
${ }^{18}$ LEMOS, Ronaldo. A sociedade contra-ataca: o marco civil como símbolo do desejo por inovação do brasil. Revista Observatório Itaú Cultural, São Paulo, Itaú Cultural, 20n. 16, p. 92-104. Disponível em: https://itsrio.org/wp-content/uploads/2017/01/OBSERVATORIO16_0.pdf. Acesso em: 26 jun. 2019. p. 95.

${ }^{19}$ GUERRA FILHO, Willis Santiago; CARNIO, Henrique Gaberllini. Metodologia jurídica políticoconstitucional e o Marco Civil da Internet: contribuição ao Direito Digital. In: MASSO, Fabiano Del; ABRUSIO, Juliana; FLORÊNCIO FILHO, Marco Aurélio (coord). Marco Civil da Internet: Lei 12965 / 2014. São Paulo: Revista dos Tribunais, 2014. p. 24.
} 
solicitações de autoridades públicas e empresas sem a análise prévia do Poder Judiciário.

É importante frisar que o Marco Civil estipula que as comunicações são, em princípio, invioláveis, e que essa inviolabilidade pode apenas ser afastada por meio de ordem judicial. O documento determina ainda que as informações pessoais dos usuários não devem ser transferidas para terceiros sem o consentimento deles. Os usuários têm o direito de ter informações claras e completas sobre a coleta, o uso, o armazenamento, o processamento e a proteção de seus dados pessoais, que somente podem ser usados para as finalidades consentidas; têm também o direito de solicitar exclusão definitiva de seus dados pessoais após o término das relações entre as partes, salvo nos casos previstos em lei.

O Marco Civil da Internet apesar de possuir diversos pontos positivos, também apresenta deficiências e insuficiências, como a repetição incansável de disposições presentes na Constituição Federal.

O texto do Marco Civil da Internet trouxe, também, normas vazias de conteúdo. Por exemplo, o art. $2^{\circ}$, IV, o qual prevê como fundamento da disciplina do uso da Internet a "abertura e a colaboração", ficando a indagação sobre de que abertura se trata e qual colaboração se pretende.

O art. $7^{\circ}$, inc. XIII, estabelece como direito dos usuários da Internet a "aplicação das normas de proteção e defesa do consumidor nas relações de consumo realizadas na Internet". O Código de Defesa do Consumidor (Lei n. 8.078/1990) foi uma das mais significativas inovações legislativas das últimas décadas, pois ambara os consumidores, economicamente hipossuficientes, fornecendo-lhes as ferramentas jurídicas necessárias para atuar em igualdade (jurídica) com os fornecedores, no intuito de obter a tutela dos seus direitos. Garantir proteção às relações de consumo, tanto presenciais quanto virtuais, com os instrumentos que o CDC oferece, como a inversão do ônus da prova, é um passo fundamental para o equilíbrio da ordem econômica e social sob o amparo do Direito.

$\mathrm{O}$ art. $5^{\circ}$ do Marco Civil da Internet trouxe definições para fins de interpretação, mas deixou de definir termos fundamentais, como: "provedor de conexão à Internet", "provedor de aplicações de Internet", "provedor responsável pela guarda dos registros" e "responsável pela transmissão, comutação e roteamento". Tais definições são relevantes, pois se referem aos principais destinatários dos deveres previstos na Lei $\mathrm{n}$. 
12.965/2014. Além disso, houve omissão sobre certos instrumentos existentes na Internet, que garantem maior segurança aos dados pessoais, como o uso da criptografia para a proteção da privacidade dos usuários. ${ }^{20}$

A sociedade digital é essencialmente colaborativa e prevalece o compartilhamento de dados, informações e conhecimentos, com acessibilidade gradual e crescente. Mas o tratamento de dados pessoais deve respeitar um dos pilares dessa sociedade, que é o respeito à privacidade, que tem relação direta com vários níveis de proteção (proteção da imagem, honra e reputação, proteção da vida privada e intimidade, proteção de informações pessoais, proteção de comunicações e proteção do domicílio). Muitos serviços na internet cobram dados e informações dos usuários, mas o Marco Civil dificulta a vida de quem quer usar, de modo indevido, os dados alheios, fazendo com que seja essencial a concordância prévia do usuário por meio de uma ciência quanto à Política de Privacidade. Não se pode olvidar que a Constituição Federal, no artigo $5^{\circ}$, incisos X e XII, protege a intimidade, a privacidade e os dados, além do que o Código Civil, no artigo 21, define que a vida privada é inviolável. Cabe ao Judiciário, quando solicitado, adotar as providências necessárias para evitar ou interromper qualquer comportamento que viole essas proteções.

A Lei n. 12.625, de 2014, como já dito, é uma lei genérica, que define os fundamentos e princípios necessários ao ambiente virtual. Em 2018, foi publicada a Lei n. 13.709, que trata de modo específico sobre a proteção dos dados pessoais, inspirada principalmente na lei da União Europeia (GDPR - General Data Protection Regulation). Essa lei fixou uma vacatio legis de 18 meses, a fim de possibilitar seu estudo e preparação por parte dos profissionais do Direito, dos cidadãos e das empresas.

Apesar do veto presidencial quanto à criação de uma autoridade fiscalizadora, essa lei foi fundamental para a entrada do Brasil na OCDE (Organização para a Cooperação e Desenvolvimento Econômico), que exigia a criação de uma legislação específica que tratasse dos dados pessoais e da privacidade dos usuários. Essa Lei é direcionada, a princípio,

\footnotetext{
${ }^{20}$ TOMASEVICIUS FILHO, Eduardo. Marco Civil da Internet: uma lei sem conteúdo normativo. Estudos Avançados. São Paulo, v. 30 n. 86, jan./abr. 2016. Disponível em: http://www.scielo.br/scielo.php?script=sci arttext\&pid=S0103-40142016000100269. Acesso em 4 mai. 2019
} 
a agentes públicos e privados e trata de diversas questões, como extraterritorialidade, dados públicos, publicidade dada pelo usuário, tratamento dos dados pessoais, direitos dos titulares, definição de conceitos importantes, dentre outras.

O Marco Civil da Internet exige que toda empresa que colete, armazene ou compartilhe dados de usuários brasileiros tenha uma política de privacidade clara e previamente apresentada para a ciência dos clientes. O usuário tem o direito de não querer passar seus dados ou de não querer que a empresa use suas informações. De outra parte, a empresa tem o direito não querer tê-lo como cliente. Com essa, lei coloca-se o consentimento do titular dos dados pessoais e informações como essencial para o respeito ao seu respectivo direito à privacidade. Antes do Marco Civil, se um usuário deixasse de ser cliente do serviço, seus dados podiam continuar com a empresa, de forma ilimitada, ou seja, para o uso com qualquer tipo de propósito. Essa realidade de violação do direito à privacidade, felizmente, mudou. Dessa forma, é possível observar que a tutela desse direito afeta, consideravelmente, a economia digital, trazendo questões a serem discutidas, tais como a forma e o indivíduo ou instituição que realizará a fiscalização das empresas, a forma de equilibrar os interesses empresariais com o respeito a esse direito (a empresa pode retirar do ar os serviços, se não obtiver as informações necessárias para a sua continuação).

Quanto à segurança digital, tem demonstrado crescente evolução com a certificação digital, cuja origem está na criação de uma tecnologia de criptografia. Em termos técnicos, a criptografia é uma ferramenta de codificação usada para envio de mensagens seguras na internet, muito utilizada no sistema bancário e financeiro. Na rede, é utilizada no formato assimétrico, isto é, codifica as informações utilizando dois códigos ou chaves (uma pública e outra privada). Para o Direito Digital, uma chave criptográfica significa que o conteúdo transmitido só pode ser lido pelo receptor que possua a mesma chave. Assim, a informação é reconhecida com a mesma validade da assinatura tradicional. A tendência é que essa tecnologia seja aprimorada para o aumento da segurança das trocas de informações via internet. Cabe ressaltar que a assinatura eletrônica é mais segura que a real, visto que a primeira é certificada, ou seja, verificada em tempo real pelo sistema de duas chaves. Além da criptografia, a assinatura digital possibilita o reconhecimento da origem de um ato e também identifica um usuário permitido em determinada atividade na internet. 
Os algoritmos, espécies de instruções simples, técnicas e matemáticas, programadas para criar certa situação ou resolver um problema também podem ser utilizados para a segurança da informação, pois é possível determinar a infraestrutura da internet e seu respectivo funcionamento por meio deles. Um programa de computador "é um algoritmo escrito em uma linguagem de programação que no final se torna milhares de operações simples que são realizadas com correntes elétricas no processador, correntes representadas pelos famosos uns e zeros, os dígitos que caracterizam o digital". ${ }^{21}$

Com a união entre os algoritmos e a tecnologias, foi possível uma revolução na sociedade. Os programadores de computador trabalham para traduzir os problemas do mundo para uma linguagem que um computador possa entender. Essa linguagem é produzida por algoritmos, que a máquina irá ler e manipular. Os algoritmos podem ser utilizados, portanto, assim para o bem, quanto para o mal, a depender de qual será sua programação, podendo influenciar e determinar os serviços digitais que são fornecidos a cada usuário.

Em suma, é possível a realização de um conjunto de medidas para que a tutela da privacidade e da intimidade, dos direitos fundamentais inerentes aos usuários da rede, seja cada vez mais efetiva. Tais medidas são o uso da certificação digital, da criptografia dos dados, da assinatura digital, além de uma correta programação técnica dos algoritmos - isto é, a promoção de uma maior e melhor arquitetura de controle e segurança dos dados pessoais. Também é necessária a atualização e fornecimento constante de softwares de antivírus. Não obstante, além dessas medidas técnicas, o Direito pode acompanhar tais mudanças, a partir da interpretação das normas já existentes com o apoio de declarações internacionais e tratados em matéria de ambiente digital. Além disso, é necessário ampliar a educação digital, pois o conhecimento dos riscos de certas condutas, dos direitos e deveres dos usuários e das técnicas de proteção de dados que podem ser utilizadas na internet, dentre outras medidas, possibilitaria o uso consciente e responsável da Internet como uma ferramenta para o exercício da cidadania

\footnotetext{
${ }^{21}$ FANJUL, Sergio C. Na verdade, o que [...] é exatamente um algoritmo? El País, Madri, 30 mar. $2018 . \quad$ Disponível em: https://brasil.elpais.com/brasil/2018/03/30/tecnologia/1522424604 741609.html. Acesso em 3 mar. 2019.
} 


\section{CONSIDERAÇÕES FINAIS}

Esta pesquisa iniciou-se a partir do interesse na área da Tecnologia atrelada ao Direito conjuntamente com as diversas ocorrências e fatos que aconteceram no Brasil e no mundo, com reflexos sobre o direito à privacidade dos indivíduos, a exemplo de diversos casos de vazamentos de dados pessoais de usuários de redes sociais, de venda de dados pessoais de por empresas, de vigilância e controle por parte de diversos governos e empresas contra pessoas titulares das informações, dentre outros.

Privacidade é a habilidade de a pessoa controlar a exposição de sua vida íntima, sua imagem, sua reputação, bem como a disponibilidade de informações acerca de si perante terceiros, a não ser nas hipóteses excetuadas por lei, quando prevaleça o interesse público no conhecimento daquela informação. De acordo com o Marco Civil da Internet, o titular do dado pessoal ou sensível deve dar seu pleno consentimento acerca do tratamento, armazenamento e utilização desses dados.

Com o advento da Lei n. 12.965/2014 (Marco Civil da Internet) e da Lei n. 13.709/2018 (Lei Geral de Proteção de Dados pessoais), o Brasil entrou no cenário mundial da tutela do direito à privacidade na rede, possibilitando a regulamentação necessária para maior segurança jurídica tanto dos indivíduos quanto das empresas e outros entes. Por serem, entretanto, leis recentes relacionadas ao vasto ambiente virtual, há ainda muitos estudos a serem realizados, aprofundando conceitos, direitos e obrigações, até porque existem poucas obras e artigos acerca do assunto.

Diversos tratados internacionais, como a Declaração Americana dos Direitos e Deveres do Homem e o Pacto de San José da Costa Rica, além da Constituição Federal Brasileira de 1988, colocam a privacidade como direito inerente e fundamental a todos os indivíduos. Por meio de diversos dispositivos tecnológicos, como a criptografia, a certificação digital, além da própria arquitetura da rede, é possível garantir maior proteção a esse direito. No entanto, é necessário ampliar a educação digital, pois o conhecimento dos riscos de certas condutas, dos direitos e deveres dos usuários e das técnicas de proteção de dados que podem ser utilizadas na internet, dentre outras medidas, possibilitaria o uso consciente $\mathrm{e}$ 
responsável da Internet como uma ferramenta para o exercício da cidadania.

\section{REFERÊNCIAS BIBLIOGRÁFICAS}

ALMEIDA, Patricia Martinez; SILVEIRA, Vladmir Oliveira da. Processo judicial eletrônico e segurança de dados: a proteção digital como novo direito humano. Revista Mestrado em Direito, Osasco, v. 13, n. 2, p. 323-343 jul-dez. 2013.

BARRETO JR., Irineu Francisco. Dignidade da pessoa humana na Sociedade da Informação. In: SIMÃO FILHO, Adalberto et al (org e coord). Direito da Sociedade da Informação: temas jurídicos relevantes. São Paulo: Quartier Latin, 2012.

BRASIL. [Constituição (1988)]. Constituição da República Federativa do Brasil. São Paulo: Revista dos Tribunais, 2000.

BRASIL. Lei $\mathbf{n}^{\circ}$ 12.965, de 23 de Abril de 2014. Estabelece princípios, garantias, direitos e deveres para o uso da Internet no Brasil.

BRASIL. Lei no 13.709, de 14 de Agosto de 2018. Lei Geral de Proteção de Dados Pessoais (LGPD).

Doneda, Danilo. Da privacidade à proteção de dados pessoais. Rio de Janeiro: Renovar: 2006.

FANJUL, Sergio C. Na verdade, o que [...] é exatamente um algoritmo? El País, Madri, 30 mar. 2018. Disponível em:

https://brasil.elpais.com/brasil/2018/03/30/tecnologia/1522424604_741609.html. Acesso em 3 mar. 2019.

FIORILLO, Celso Antônio Pacheco. O Marco Civil da Internet e o Meio Ambiente Digital na Sociedade da Informação. 2. ed. São Paulo: Editora Saraiva, 2015

GUERRA FILHO, Willis Santiago; CARNIO, Henrique Gaberllini. Metodologia jurídica político-constitucional e o Marco Civil da Internet: contribuição ao Direito Digital. In: MASSO, Fabiano Del; ABRUSIO, Juliana; FLORÊNCIO FILHO, Marco Aurélio (coord). Marco Civil da Internet: Lei 12965 / 2014. São Paulo: Revista dos Tribunais, 2014 .

GUIDI, Guilherme Berti de Campos. Modelos regulatórios para proteção de dados pessoais. In: BRANCO, Sérgio; TEFFÉ, Chiara de. Privacidade em perspectiva. Rio de Janeiro: Lumen Juris, 2018. 
HABERMAS, Jürgen. Mudança estrutural na esfera pública: investigações quanto a uma categoria da sociedade burguesa. 2.ed. Rio de Janeiro: Tempo Brasileiro, 2003.

LEONARDI, Marcel. Tutela e privacidade na Internet. São Paulo: Editora Saraiva, 2012.

LEMOS, Ronaldo. A sociedade contra-ataca: o marco civil como símbolo do desejo por inovação do brasil. Revista Observatório Itaú Cultural, São Paulo, Itaú Cultural, n. 16, p. 92-104. Disponível em: https://itsrio.org/wp-

content/uploads/2017/01/OBSERVATORIO16_0.pdf. Acesso em: 26 jun. 2019.

PINHEIRO, Patrícia Peck. Direito Digital. 6 ed. São Paulo: Editora Saraiva, 2016.

SILVA, Letícia Brum da; SILVA, Rosane Leal da. A proteção jurídica de dados pessoais na internet: análise comparada do tratamento jurídico do tema na União Europeia e no Brasil. Disponível em:

http://www.publicadireito.com.br/artigos/?cod=e4d8163c7a068b65. Acesso em 25 set. 2019.

TOMASEVICIUS FILHO, Eduardo. Marco Civil da Internet: uma lei sem conteúdo normativo. Estudos Avançados. São Paulo, v. 30 n. 86, jan./abr. 2016. Disponível em: http://www.scielo.br/scielo.php?script=sci_arttext\&pid=S0103-40142016000100269. Acesso em 4 mai. 2019. 